\title{
Developmental Origins of Astrocyte Heterogeneity: The Final Frontier of CNS Development
}

\author{
Lesley S. Chaboub ${ }^{a, b}$ Benjamin Deneen ${ }^{a-c}$ \\ a Program in Developmental Biology, ${ }^{b}$ Center for Cell and Gene Therapy, and ${ }^{\mathrm{C}}$ Department of Neuroscience, \\ Baylor College of Medicine, Houston, Tex., USA
}

\section{Key Words}

Heterogeneity · Astrocyte - Embryonic development •

Patterning

\begin{abstract}
Astrocytes are the most abundant cell type in the central nervous system, have diverse physiological roles in both health and disease, and exhibit phenotypic heterogeneity. In spite of the overwhelming evidence that astrocytes are a diverse population, there has been relatively little consideration of their molecular heterogeneity. In this review, we will summarize what is known about the heterogeneity of astrocytes and outline challenges that have limited studies understanding their molecular diversity. Approaches that have sought to overcome these limitations will be discussed, with an emphasis on recent progress in the field of developmental gliogenesis, which has revealed that positional identity during embryogenesis is an organizing feature of astrocyte diversity. These recent findings, coupled with emerging technologies that allow for direct isolation of astrocyte populations, have led us to propose that approaches rooted in astrocyte development may be the key to unlocking this immense, untapped diversity.

Copyright $\odot 2012$ S. Karger AG, Basel
\end{abstract}

\section{KARGER}

Fax +41613061234

E-Mail karger@karger.ch

www.karger.com
(C) 2012 S. Karger AG, Basel

$0378-5866 / 12 / 0345-0379 \$ 38.00 / 0$

Accessible online at:

www.karger.com/dne

\section{Introduction}

Astrocytes were first described by Virchow [1] in 1846 and were originally thought to be a homogenous population of cells which function to support neurons. Subsequently, Camillo Golgi and Ramon y Cajal observed diverse astrocyte morphologies in the human cerebellum, laying the foundation for the dissection and study of this potentially immense cellular diversity $[2,3]$. Since the time of Golgi and Cajal, numerous astrocyte morphologies across various regions of the central nervous system (CNS) have been described $[4,5]$, hinting that an extensive reservoir of molecular heterogeneity lies within these diverse astrocyte populations. Supporting this idea of molecularly diverse subpopulations of astrocytes are the observations that they are functionally diverse and directly contribute to a myriad of cellular processes essential for normal CNS physiology, including: synaptogenesis, neurotransmission, trophic regulation and bloodbrain barrier formation, to name a few $[6,7]$. Moreover, astrocyte-like cells in the adult subventricular zone or subgranular zone can function as multipotent stem cells in vivo and are the major source of adult neurogenesis in the olfactory bulb and hippocampus $[8,9]$. This extensive functional diversity, when coupled with morphological

Benjamin Deneen

Department of Neuroscience, Baylor College of Medicine

One Baylor Plaza

Houston, TX 77030 (USA)

E-Mail deneen@bcm.edu 
heterogeneity strongly suggests the existence of molecularly distinct subtypes of astrocytes. However, whether these diverse functions can be performed by all astrocytes, or are distributed across a spectrum of distinct subpopulations remains an open question. Therefore, linking molecular and functional heterogeneity of astrocytes has either become the 'elephant in the room' or the 'holy grail', depending upon one's perspective (neuron-centric vs. glial-centric, respectively).

The goal of this review is to summarize what we know about astrocytes and their heterogeneity, highlighting recent experimental approaches that have been used to dissect their molecular diversity in vivo. Indeed, several reviews have focused on the functional diversity of astrocytes $[6,7]$, and on the general knowledge so far gained $[4,10]$. However, here we will discuss what is known about the molecular heterogeneity of astrocytes and the inherent limitations of characterizing their diversity. Furthermore, we will discuss what is known about the developmental mechanisms that control astrocyte heterogeneity and provide perspective on how these paradigms may guide the use of existing technologies to study these cells and understand their contributions to normal CNS physiology and disease.

\section{Challenges in the Study of Astrocyte Development}

If astrocytes are the most abundant cell type of the CNS, why do we know so little about them? Studies on astrocyte development and function have been hindered over the years for two key reasons: (1) differences across species in astrocyte/glial biology and (2) the lack of a clearly defined developmental endpoint. A common strategy to understand a developmental process is to study it in lower organisms and determine whether the regulatory paradigms are conserved in higher organisms. In the late 80 s/early 90 s, several groups employed this strategy to the study of neurogenesis and found that bHLH transcription factors controlling Drosophila neurogenesis also control neurogenesis in mammals [11-13], paving the way for our current understanding of neurogenesis in the CNS. When this same approach was applied to the study of astrocytes/glial cells, it was not met with the same success. In Drosophila, the generation of glial cells is controlled by the transcription factor $\mathrm{gcm}$ (glial cells missing) [14, 15]; however, manipulation of the mammalian homologue of $\mathrm{gcm}$ in mouse models did not affect the generation of glial cells (astrocytes or oligodendrocytes) [16-19]. This key finding indicates that the de- velopmental origins of astrocytes/glial cells are fundamentally different across species, suggesting that astrocyte/glial contribution to the functioning CNS also differs across species. Indeed, both the number and complexity of astrocytes has increased over evolution [20, 21], further complicating the use of lower organisms for the study of astrocyte development, diversity, and function. Nevertheless, in spite of these key differences, some aspects of astrocyte function are likely to be conserved in invertebrate models, warranting the use of these models in the study of astrocyte/glia function.

Another important limitation is the lack of a clearly defined developmental endpoint for astrocytes, which is crucial for the identification of terminally differentiated cells and has aided the study of other cell types in the CNS. Terminally differentiated neurons are postmitotic, have distinct morphologies (including axons and dendrites) and activities [22]. Likewise terminally differentiated oligodendrocytes are also postmitotic, have a distinct morphology, and express a set of myelin genes that are essential for their singular role in myelination [23]. These properties can be used to measure progress through a developmental lineage and as criteria for functional studies both in vitro and in vivo. Conversely, astrocytes do not play by the same set of rules. GFAP-expressing astrocyte populations retain mitotic potential, as evidenced by their robust local proliferation in the postnatal cortex and BrdU-labeling studies in the brain and spinal cord $[24,25]$. These properties suggest that mature astrocytes are a 'moving target' and thus, unlike differentiated neurons and oligodendrocytes, may not be developmentally or functionally static, especially in vitro. Astrocytes demonstrate a variety of morphologies and when coupled with their functional diversity [6], it results in a situation where it can be difficult to know what population you are studying and which properties to test for, hindering functional studies that might serve to decode morphological/ molecular relationships. Collectively, these properties have conspired to make the study of astrocyte development and function enigmatic and reinforce the importance of assigning unique molecular signatures to functional subtypes of astrocytes.

\section{Morphological Heterogeneity of Astrocytes}

Since a major limitation in our understanding of astrocytes stems from their immense diversity, we will begin with the most recognizable form of heterogeneity, i.e. morphology. Since the time of Cajal, astrocytes have been 
categorized into 2 broad morphologies: protoplasmic with long unbranched processes and fibrous astrocytes with short and highly branched extensions $[3,4]$. Protoplasmic astrocytes are found in the gray matter and generally express $S 100 \beta$, while fibrous astrocytes are located within the white matter and express GFAP [26, 27]. Functionally, protoplasmic astrocytes associate with both synapses and endothelial cells, thus directly participating in the 'neurovascular unit' [10, 28-30]. Less is known about the function of fibrous astrocytes, but their location in the white matter suggests they may participate in myelination [27]. Collectively, these observations suggest a link between astrocyte morphology and function, supporting the possibility that molecularly distinct astrocytes perform unique functions.

Another way of identifying morphologically distinct subpopulations of astrocytes is to compare their morphologies across brain regions. Indeed, the presence and/ or proportion of protoplasmic and fibrous astrocytes varies across brain regions, indicating regional heterogeneity of these populations. Similarly, a recent study identified 9 morphologically distinct GFAP- or S100 $\beta$-expressing astrocytes [5], distributed in varying proportions across different brain regions, supporting the notion that different brain regions, which perform different motor and/or cognitive functions, are likely to harbor astrocytes with distinct molecular and functional properties. While gross morphology can be used as an entry point into the dissection of astrocyte heterogeneity, it does not always correlate with function. For example, Bergmann and Muller glia are specialized 'radial' astroglia found in the cerebellum and retina, respectively, that are morphologically similar to radial glia, possessing long processes that extend to the pia surface [31,32]. Like radial glia, during development Bergmann glia provide a substrate upon which granule cell precursors migrate [33]; however, Muller glia have not been linked to precursor migration and are thought to have a role in regeneration [34]. While their role in development may differ, in the adult both Bergmann and Muller glia are thought to modulate synaptic activity and thus function similar to protoplasmic astrocytes $[35,36]$. That Bergmann and Muller glia are morphologically distinct from protoplasmic astrocytes, yet have similar functions, further supports the notion that astrocyte morphology can be dissociated from function. Together, these observations indicate that categorizing functional groups of astrocytes based on gross morphology does not provide sufficient enough resolution to make predictions about the function of a given morphological class across the CNS.

Developmental Origins of Astrocytes

\section{Approaches to Dissecting Astrocyte Heterogeneity}

The coupling of morphological and functional properties of regionally distinct astrocytes has provided a limited understanding of their heterogeneity and highlights the importance of uncovering the molecular underpinning of these morphologically and functionally diverse populations across different regions of the CNS. While cataloging molecular signatures of morphologically distinct astrocyte subpopulations across a variety of brain regions is a worthwhile endeavor, the reality is that the field of astrocyte biology has been hindered for years by a paucity of reliable markers. While developmental and functional studies on neurons and oligodendrocytes have been facilitated by the existence of subtype and stage-specific markers, analogous markers for astrocyte lineages have not existed. Traditionally, a vast majority of studies on astrocytes have relied on the expression of GFAP, a marker of terminally differentiated astrocytes that poorly labels protoplasmic astrocytes (fig. 1) $[4,27]$ and is expressed in adult type $B$ multipotent cells of the rodent subventricular zone $[8,33]$, indicating that it cannot be used as a stage-specific marker. Moreover, GFAP becomes upregulated in reactive and cultured astrocytes reflecting a state quite different from that of normal, resting astrocyte populations $[10,37,38]$. Given the limited number of astrocyte markers and their importance in dissecting heterogeneity, a major directive in the field of astrocyte development is the identification of new markers, both general and subtype specific. Below is an overview of recent approaches that have been implemented in the identification of new astrocyte markers.

\section{Approach 1: Identify Region-Specific Differences}

Given that different regions of the adult brain contain astrocytes with vastly different morphologies $[3,5]$, it follows that these populations likely have unique molecular signatures. In one such study, Bachoo et al. [39] compared the gene expression profiles of astrocytes from various developmental stages and regions, isolated using both in vitro culture and complementary in vivo samples. Here the goal was to identify common gene signatures across samples that delineated a unified astrocyte profile. Instead, they found that each brain region contained unique molecular profiles and that significant differences existed between cultured astrocytes and primary astrocytes. In spite of these limitations, several new markers of astrocytes were validated in vivo, including Id 3 and AldoC (fig. 1). More recently, Yeh et al. [40] cultured astrocytes isolated from the cortex, cerebellum, optic nerve and 
Fig. 1. Expression of Aldh1l1 in spinal cord astrocytes. Spinal cord from P2 mice from the Aldh1l1-GFP mouse line stained with GFAP and AldoC. Alhd1l1 is expressed in both fibrous (white matter) and protoplasmic (gray matter) astrocytes. Note that GFAP-expressing astrocytes are generally restricted to the white matter and have fibrous morphologies. Reproduced from Tsai et al. [44] with permission.
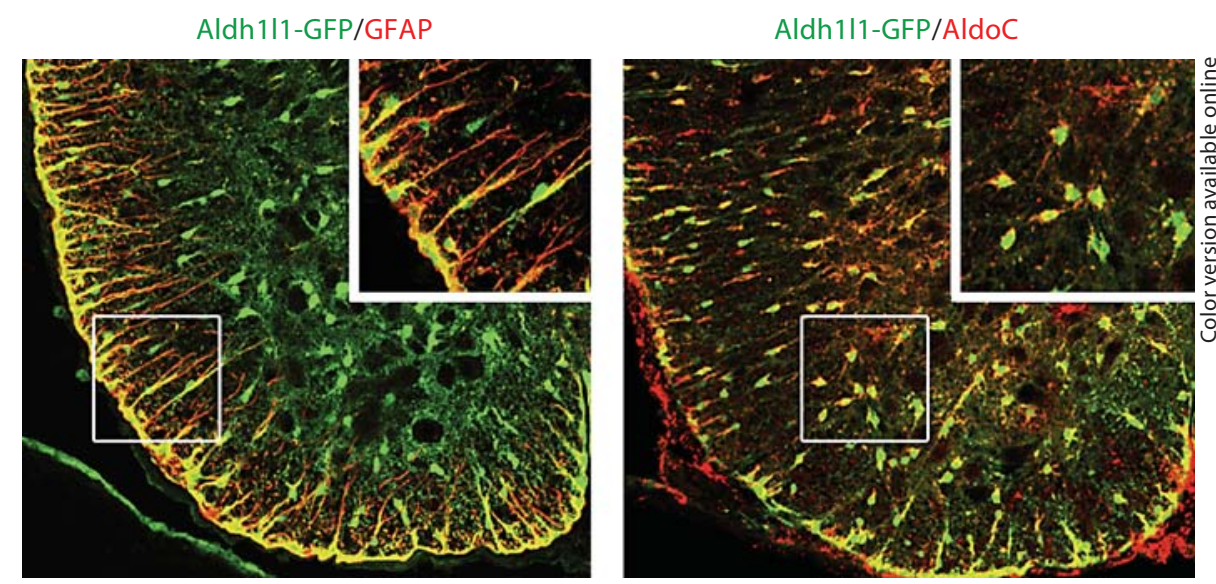

brainstem and compared their gene expression profiles. These studies found that each population contained both common and unique cohorts of genes, with astrocytes from the optic nerve having the most divergent gene expression profile. While the data generated from this study contains a wealth of information, limited in vivo confirmation of candidates was performed, as the broader goal of this study was to identify region-specific expression of tumor suppressor genes. That different brain regions contain molecularly distinct astrocytes in vivo was confirmed when Doyle et al. [41] examined the heterogeneity of directly isolated astrocytes from different brain regions using translating ribosome affinity purification coupled with BAC transgenics. Their data indicated that astrocytes isolated from the cortex and the cerebellum have different gene clustering data sets. While the use of state-of-the-art mouse tools to directly examine molecular heterogeneity of region-specific astrocytes represents a significant advance in the field, these studies did not, however, validate any candidate genes that could be used to mark astrocytes from different regions.

\section{Approach 2: Comparison of Astrocytes with Other Neural Cell Types}

Another approach to identify novel markers of astrocytes is to compare their expression profiles with mature neurons and oligodendrocytes. Up to this point, a major limitation in the use of in vitro systems to study astrocytes is that they are mostly derived from a small, proliferating glial precursor population that demonstrates immature phenotypes, but expresses several mature markers [42]. Thus it is likely that the derivates of these cells propagated in culture do not fully recapitulate the in vivo astrocyte constituency. In a landmark paper by the
Barres group [43], a novel approach to the purification and culture of glial precursors was developed that allowed for characterization and unambiguous comparison of the gene expression profiles of astrocytes, neurons, and oligodendrocytes. Using an S100ß-EGFP transgenic mouse line, classic immunopanning techniques were coupled with FACS analysis and applied to acute cultures derived from the forebrain. This resulted in highly purified astrocyte and oligodendrocyte cultures that could be used as a substrate for gene expression profiling studies and resulted in the generation of the astrocyte transcriptome database. In addition to providing an extensive cataloging of the molecular profile of astrocytes, several markers were validated in vivo, including Aldh1l1, which is rapidly becoming the 'new' standard marker of astrocytes, marking both fibrous and protoplasmic astrocytes (see below and fig. 1) [44]. While delineating the transcriptome of astrocytes represents a major advance in our understanding of their biology, these studies do not provide any additional insight into their heterogeneity.

\section{Approach 3: Functional Properties as Markers of Heterogeneity}

Given the diverse roles of astrocytes, another source of heterogeneity are the molecules associated with these functions [6]. In particular, several studies have found that astrocytes from different regions demonstrate heterogeneity in their expression of ion channels and coupling molecules. For example, the $\mathrm{K}^{+}$channel, Kir4.1, is enriched in astrocytes of the ventral horn of the spinal cord compared to those of the dorsal horn and corresponds with the rates of $\mathrm{K}^{+}$uptake by astrocytes in local dorsal and ventral populations [45]. Glutamate receptors 
provide an example of regional heterogeneity, where functional NMDA receptors have been reported in cortical and spinal cord astrocytes and Bergmann glia of the cerebellum [46-48], but not in the hippocampus [49]. Along these same lines, it is interesting to note that hippocampal astrocytes were found to be subdivided into at least three electrophysiologically distinct types [50], further suggesting ion channel heterogeneity amongst astrocytes. Coupling via GAP junctions is another feature of astrocytes that demonstrates regional heterogeneity, where the expression of connexin 43 and 30 is more pronounced in the barrel field compared to the septal region, or other regions of the cortex [51]. In each of these examples, especially for the channel proteins, expression of the given molecule is not restricted to astrocytes, as they are also expressed on neurons and therefore unlikely to represent astrocyte-specific markers.

An alternative approach that also employs a functional perspective on molecular heterogeneity is to use molecules that are specifically associated with astrocyte function. One astrocyte-specific function is to remove extracellular glutamate from synapses, which is crucial for preventing excitotoxicity and modulating neurotransmission [52-54]. This function is performed by the glutamate transporters, GLT-1 and GLAST, which developmental studies indicated are specifically expressed on astrocytes and astrocyte precursors [55-57]. In a study by the Rothstein group, GLT-1 and GLAST transgenic $\mathrm{BAC}$ reporters were generated and found to have regionspecific activity, where in the adult GLT-1 demonstrated expression in the cortex, gray matter areas of the hippocampus, and spinal cord, while GLAST was expressed in the cerebellum, dentate gyrus of the hippocampus, and spinal cord [58]. Interestingly, intercrossing these mouse lines revealed heterogeneity within the regions that expressed both reporters, identifying distinct combinations of single-GLAST/DsRED+, single-GLT-1/EGFP+, or double-GLAST/DsREd+;GLT1/EGFP+ subpopulations within the spinal cord, cortex, hippocampus, and cerebellum. More recently, similar approaches were implemented using GLT-1 and Aldh1l1 BAC reporter mice and combinations of single and double reporter-positive populations were identified in the spinal cord and cortex, suggesting that GLT-1 and Aldh1l1 expression also marks subpopulations of astrocytes [59]. These studies clearly indicate the presence of both regional and local heterogeneity in astrocyte populations in the CNS and suggest the use of combinations of astrocyte-specific molecules as tools for identifying subpopulations of astrocytes.

Developmental Origins of Astrocytes

\section{Developmental Markers of Astrocytes}

The use of GLAST and GLT-1 to identify local subpopulations of astrocytes is based on the observation that they are expressed in developing astrocyte precursors during embryogenesis and early postnatal stages. This highlights the importance of using developmental studies as a guide in the identification of general and subtypespecific markers of astrocytes. While our understanding of the molecular controls of early astrocytogenesis remains rudimentary, several developmental studies have identified new markers of astrocyte precursors, albeit with some limitations. For example, the first indication of glial specification is marked by the induction of NFIA/B [60] and GLAST [57] at E11.5. These markers continue to be expressed in astrocytes during precursor migration (E13.5-E16.5) and thus do not become truly astrocyte-specific until several days after specification in the ventricular zone (VZ). One caveat is that both NFIA/B and GLAST are also expressed in oligodendrocyte precursors. Other reported markers of astrocytes and/or their precursors include FGFR3 [61], FABP7 [62]/BLBP [63], and Sox9 [64]. However, many of these markers are also expressed during neurogenic stages, thus do not exclusively mark VZ cells committed to the astrocyte lineage and therefore do not specifically mark astrocyte precursors. Nevertheless, in the future, intersectional approaches like those taken with GLAST and GLT-1 [58], with these (or other) markers, may reveal new layers of astrocyte and astrocyte precursor heterogeneity.

\section{Patterning and Astrocytes: A Way to Diversify}

A conserved developmental strategy used to generate cellular diversity within a given lineage is the patterning of embryonic tissue. In the developing CNS, patterning has been shown to control the generation of various subpopulations of projection neurons and interneurons in the spinal cord and forebrain [65]. Neural tube patterning is the process by which extrinsic morphogenic signals (BMP, Wnt, Shh) are integrated into neuroepithelial populations lining the VZ and converted to cell-intrinsic transcription factor expression.

In the spinal cord, this results in a set of domains along the dorsal ventral axis, each expressing a unique combination of these HD transcription factors, which ultimately gives rise to distinct subpopulations of interneurons or motor neurons. After the initial wave of neurogenesis (approx. E9-E11), the VZ populations begin generating 
glia around E12.5, a developmental transition regulated by Sox 9 and NFIA $[60,64,66]$. While NFIA and Sox 9 are key regulators of gliogenesis and eventual markers of astrocytes, they do not mark distinct subpopulations. This raises the question of whether the patterning mechanisms that control the generation of neuronal diversity are reutilized during gliogenesis and serve to organize local astrocyte heterogeneity. Previous studies have linked morphogens associated with patterning to astrocyte heterogeneity without making a direct connection to the 'transcriptional codes' that control pattern formation. For example, in vitro studies revealed that astrocytes cultured in the presence of BMPs have distinct morphologies from those cultured in LIF [67]. While the presence of these subpopulations has not been rigorously validated in vivo, deletion of BMPRs in astrocytes influences astrocyte morphology and response during spinal cord injury [68]. More recent studies indicate that local subsets of astrocytes in the forebrain receive Shh signaling, as marked by Glil reporter mice [69]. Moreover, deletion of the Shh coreceptor smoothened (Smo) results in reactive gliosis specifically in the Glil-expressing astrocytes, implicating Shh signaling in the regulation of a distinct astrocyte subpopulation in vivo [69]. These studies implicate BMP and Shh in the diversification of astrocytes and suggest that they may do so by using patterning-independent mechanisms.

\section{Embryonic Origins of Astrocyte Heterogeneity}

The first evidence that glial cell diversity is the result of patterning came from the observation that a vast majority $(>85 \%)$ of spinal cord oligodendrocytes are derived from the $\mathrm{pMN}$ domain, a ventral domain that specifically expresses the bHLH transcription factor Olig2, while the remaining domains (p1-p3) generate astrocytes $[70,71]$. The concept that patterning is directly linked to the generation of astrocytes arose indirectly from analysis of the Olig2-null mice, where in the absence of Olig2, the $\mathrm{pMN}$ domain is converted to a supernumerary copy of the adjacent domain (p2), and the cells that were originally fated to become oligodendrocytes are converted to astrocytes [72, 73]. Subsequently it was found that crossrepressive interactions between Olig2 and Scl operate at the interface of the pMN and $\mathrm{p} 2$ domains to control astrocyte versus oligodendrocyte fate decisions [74]. Together, these observations indicate that astrocytes are generated from a restricted region of the neural tube, and further support the notion of separate domains for oligo-

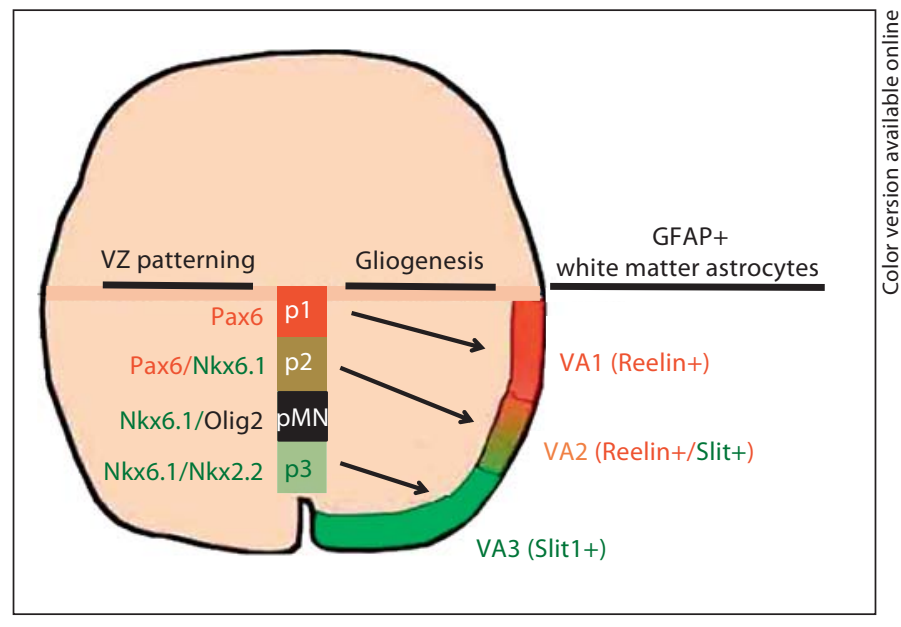

Fig. 2. Schematic illustrating the VZ origins and the white matter destinations of VA1-VA3 astrocyte populations in the spinal cord. Note that the positions of VA1-VA3 in the white matter mirror their positions along the dorsal/ventral axis of the $\mathrm{VZ}$ during specification. Reelin and Slit are also expressed in the VZ populations during specification, and Pax6 and Nkx6.1 expression is maintained in white matter astrocyte populations after migration and differentiation.

dendrocyte and astrocyte production along the dorsal/ ventral axis of the embryonic spinal cord.

While these initial studies provided the first evidence that progenitor patterning is an organizing principle controlling the generation of glial diversity (i.e. oligodendrocyte versus astrocyte), they did not decode the link between patterning, positional identity, and molecularly distinct subpopulations of astrocytes. Subsequent studies in the Anderson lab made the direct link between patterning and astrocyte diversity in the spinal cord by analyzing the gene expression profiles of astrocytes generated in the absence of Olig2 [75]. These studies identified the patterning transcription factors Pax6 and Nkx6.1, as well as Reelin and Slit as highly expressed in these converted astrocyte populations. Analysis of their temporal and spatial expression patterns during gliogenesis demonstrated that the combinatorial expression of Pax6 and Nkx6.1 marks three subtypes of ventral white matter astrocytes (termed VA1, VA2, and VA3), which can be identified, based on their patterns of Slit1 and Reelin expression. These astrocyte subtypes exhibit positional identity and are organized into domains of the ventral white matter along the dorsal-ventral axis, which mirror the dorsalventral arrangement of their progenitors in the p1, p2 and p3 VZ domains at earlier stages (fig. 2). VA1 astrocytes 
Fig. 3. Top-down approach to defining local astrocyte heterogeneity. Colored circles represent different brain regions. 'A' represents a given astrocyte subpopulation and ' $F$ ' represents a given function of astrocytes. The colored dashed lines between ' $\mathrm{A}$ ' and ' $\mathrm{F}$ ' represent the possibility that a given astrocyte subpopulation may perform more than one function. The black dashed lines between examples represent comparison between different regions at different levels of the 'top-down' paradigm, and represent the 'lateral approach' to interrogating astrocyte heterogeneity. For colors, see online version.

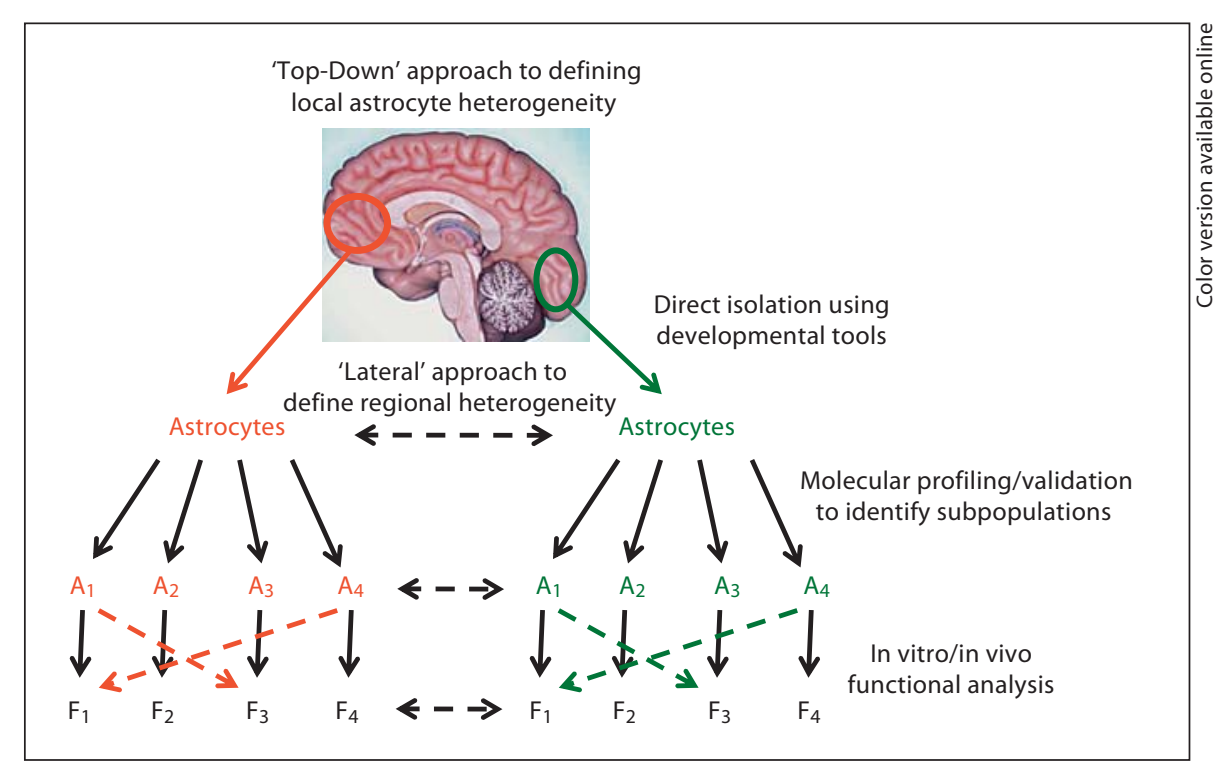

$(\mathrm{Pax} 6+/$ Reelin +$)$ are the most dorsal and are located in the lateral spinal cord white matter, while VA3 astrocytes $(\mathrm{Nkx} 6.1+$, Slit1+) are the most ventral and VA2 astrocytes (Pax6+, Nkx6.1+, Reelin+, Slit1+) are located in an in-between ventral-lateral white matter domain. Functional studies revealed that Pax6 is essential for VA1 and VA2 astrocyte identity by promoting Reelin and repressing Slit1 expression, indicating that cross-repressive interactions controlling $\mathrm{VZ}$ patterning also control astrocyte subtype identity. Specification of VA3 astrocytes appears to be dependent on multiple factors including Nkx6.1 and Nkx2.2, suggesting the involvement of other patterning genes in the specification of astrocyte subtypes. In sum, these studies indicate that patterning and positional identity control the diversification of glial subtypes and, importantly, white matter astrocytes in the spinal cord.

Recently, the concept that astrocytes are patterned in the spinal cord was elegantly confirmed using conditional Cre lines that are specifically active in VZ domains along the dorsal/ventral axis of the spinal cord to trace the fate of astrocyte progenitors derived from these domains [44]. Importantly, these approaches were extended to the developing forebrain and met with similar results, suggesting that patterning may be a generalized principle of astrocyte diversity throughout the CNS. Moreover, this study found that both white matter (fibrous) and gray matter (protoplasmic) astrocytes are derived from these domains, indicating common VZ origins of these populations. Interestingly, the lineage tracing approach allowed for careful analysis of astrocyte precursor migra- tory patterns and revealed a stereotypical radial migration pattern that is congruent with their VZ sites of origin and stable throughout the life of the animal and after injury. Taken together, these patterning studies indicate astrocyte diversity in the spinal cord and forebrain is prespecified into positionally distinct subtypes by a homeodomain transcription factor code and these spatial relationships are maintained during migration, differentiation, and throughout adulthood.

\section{Conclusions}

That astrocytes comprise approximately $50 \%$ of the cellular constituency of the CNS [76], coupled with the regional complexities of the adult brain, make dissecting their heterogeneity across the adult brain a daunting task. Several groups have investigated astrocyte heterogeneity using 'lateral' approaches that involve comparison of gene signatures of astrocytes derived from different brain regions [39, 41, 43]. Given recent insights from developmental studies on astrocytes in the spinal cord and forebrain, we propose a targeted, 'top-down' approach that interrogates local heterogeneity within a given brain region (fig. 3). This approach will ideally make use of newly developed intersectional BAC transgenic and translating ribosome affinity purification technologies [41, 58], and established lineage tracing methods to directly isolate bulk astrocyte populations and delineate their gene expression profiles, ultimately uncovering their molecu- 
lar heterogeneity. These studies will be complemented by in vitro studies that employ recent advances in glial precursor and astrocyte culturing techniques that can be used for functional studies [77]. The key to successful implementation of this model is a thorough understanding of astrocyte development throughout the CNS, as many of the tools required to implement these technologies entail prior knowledge of astrocyte or astrocyte precursor development. There is increasing evidence that astrocytes, like neurons, are patterned during early embryogenesis $[44,75]$; therefore, existing mouse tools that make use of morphogens and transcription factors associated with patterning could serve as a starting point for these studies.

The use of paradigms associated with patterning or glial development to dissect astrocyte heterogeneity is convenient; however, it raises the question of whether astrocytes from other CNS regions are similarly patterned. This is a key question, as different regions of the CNS use different molecular and cellular developmental programs, thus what works in the spinal cord or forebrain may not be applicable to the hippocampus. Because the developing CNS is not necessarily a 'unified field', a com- prehensive understanding of the molecules controlling patterning and early gliogenesis of a brain region to be studied is essential. Moreover, recent studies indicate that astrocytes from the spinal cord are relatively static throughout adulthood and seemingly tethered to their sites of origin in the VZ [44]. Whether this is true in other regions of the CNS will have a profound effect on how these patterning approaches are implemented. The ultimate goal of understanding astrocyte heterogeneity is to determine if subpopulations of astrocytes exist and whether they perform specific functions. Given recent insights into their developmental and functional diversity, this seems likely, but nevertheless remains an open question and one of the final frontiers of developmental neuroscience.

\section{Acknowledgements}

We apologize to those whose work we could not cite due to space limitations. This work was supported by funding from the Cancer Prevention and Research Institute of Texas RP101499 (LSC), Sontag Foundation (BD), and National Institutes of Health R01-NS071153 (BD).

\section{References}

1 Virchow R: Über das granulierte Ansehen der Wandungen der Gehirnventrikel. Allg Z Psychiatr 1846;3:242-250.

-2 Garcia-Marin V, Garcia-Lopez P, Freire M: Cajal's contributions to glia research. Trends Neurosci 2007;30:479-487.

3 Ramón y Cajal S: Histologie du système nerveux de l'homme et des vertébrés. Paris, Maloine, 1909.

4 Sofroniew MV, Vinters HV: Astrocytes: biology and pathology. Acta Neuropathol 2010; 119:7-35.

5 Emsley JG, Macklis JD: Astroglial heterogeneity closely reflects the neuronal-defined anatomy of the adult murine CNS. Neuron Glia Biol 2006;2:175-186.

$\checkmark 6$ Matyash V, Kettenmann H: Heterogeneity in astrocyte morphology and physiology. Brain Res Rev 2010;63:2-10.

7 Allen NJ, Barres BA: Neuroscience: glia More than just brain glue. Nature 2009;457: 675-677.

$>8$ Doetsch F, Caille I, Lim DA, Garcia-Verdugo JM, Alvarez-Buylla A: Subventricular zone astrocytes are neural stem cells in the adult mammalian brain. Cell 1999;97:703-716.

9 Eckenhoff MF, Rakic P: Nature and fate of proliferative cells in the hippocampal dentate gyrus during the life span of the rhesus monkey. J Neurosci 1988;8:2729-2747.
10 Molofsky AV, Krenick R, Ullian E, Tsai HH, Deneen B, Richardson WD, Barres BA, Rowitch DH: Astrocytes and disease: a neurodevelopmental perspective. Genes Dev 2012; 26:891-907.

11 Johnson JE, Birren SJ, Anderson DJ: Two rat homologues of Drosophila achaete-scute specifically expressed in neuronal precursors. Nature 1990;346:858-861.

12 Ben-Arie N, McCall AE, Berkman S, Eichele G, Bellen HJ, Zoghbi HY: Evolutionary conservation of sequence and expression of the bhlh protein atonal suggests a conserved role in neurogenesis. Hum Mol Genet 1996;5: 1207-1216.

13 Lee JE: Basic helix-loop-helix genes in neural development. Curr Opin Neurobiol 1997;7: 13-20.

- 14 Hosoya T, Takizawa K, Nitta K, Hotta Y: Glial cells missing: a binary switch between neuronal and glial determination in drosophila. Cell 1995;82:1025-1036.

15 Jones BW, Fetter RD, Tear G, Goodman CS Glial cells missing: a genetic switch that controls glial versus neuronal fate. Cell 1995;82: 1013-1023.

16 Kammerer M, Pirola B, Giglio S, Giangrande A: GCMB, a second human homolog of the fly glide/gcm gene. Cytogenet Cell Genet 1999;84:43-47.
17 Kanemura Y, Hiraga S, Arita N, Ohnishi T, Izumoto S, Mori K, Matsumura H, Yamasaki M, Fushiki S, Yoshimine T: Isolation and expression analysis of a novel human homologue of the Drosophila glial cells missing $(\mathrm{gcm})$ gene. FEBS Lett 1999;442: 151-156.

18 Nait-Oumesmar B, Copperman AB, Lazzarini RA: Placental expression and chromosomal localization of the human $\mathrm{gcm} 1$ gene. J Histochem Cytochem 2000;48:915922.

19 Kim J, Jones BW, Zock C, Chen Z, Wang H, Goodman CS, Anderson DJ: Isolation and characterization of mammalian homologs of the Drosophila gene glial cells missing. Proc Natl Acad Sci USA 1998;95:1236412369.

20 Nedergaard M, Ransom B, Goldman SA: New roles for astrocytes: redefining the functional architecture of the brain. Trends Neurosci 2003;26:523-530.

21 Oberheim NA, Takano T, Han X, He W, Lin JH, Wang F, Xu Q, Wyatt JD, Pilcher W, Ojemann JG, Ransom BR, Goldman SA, Nedergaard M: Uniquely hominid features of adult human astrocytes. J Neurosci 2009;29:32763287. 
22 Jessell TM, Sanes JR: Development. The decade of the developing brain. Curr Opin Neurobiol 2000;10:599-611.

23 Emery B: Regulation of oligodendrocyte differentiation and myelination. Science 2010; 330:779-782.

-24 Ge WP, Miyawaki A, Gage FH, Jan YN, Jan LY: Local generation of glia is a major astrocyte source in postnatal cortex. Nature 2012; 484:376-380.

-25 Tien AC, Tsai HH, Molofsky AV, McMahon M, Foo LC, Kaul A, Dougherty JD, Heintz N, Gutmann DH, Barres BA, Rowitch DH: Regulated temporal-spatial astrocyte precursor cell proliferation involves BRAF signalling in mammalian spinal cord. Development 2012;139:2477-2487.

-26 Bignami A, Eng LF, Dahl D, Uyeda CT: Localization of the glial fibrillary acidic protein in astrocytes by immunofluorescence. Brain Res 1972;43:429-435.

27 Miller RH, Raff MC: Fibrous and protoplasmic astrocytes are biochemically and developmentally distinct. J Neurosci 1984;4:585592.

28 Peters A, Palay SL, Webster HD: The Fine Structure of the Nervous System, ed 3. New York, Oxford University Press, 1991.

-29 Bushong EA, Martone ME, Ellisman $\mathrm{MH}$ : Examination of the relationship between astrocyte morphology and laminar boundaries in the molecular layer of adult dentate gyrus. J Comp Neurol 2003;462:241-251.

- 30 Bushong EA, Martone ME, Jones YZ, Ellisman MH: Protoplasmic astrocytes in CA1 stratum radiatum occupy separate anatomical domains. J Neurosci 2002;22:183-192.

- 31 Reichenbach A, Siegel A, Rickmann M, Wolff JR, Noone D, Robinson SR: Distribution of Bergmann glial somata and processes: implications for function. J Hirnforsch 1995;36:509-517.

- 32 Hollander H, Makarov F, Dreher Z, van Driel D, Chan-Ling TL, Stone J: Structure of the macroglia of the retina: sharing and division of labour between astrocytes and Muller cells. J Comp Neurol 1991;313:587-603.

-33 Rakic P: Neuron-glia relationship during granule cell migration in developing cerebellar cortex. A Golgi and electronmicroscopic study in Macacus Rhesus. J Comp Neurol 1971;141:283-312.

- 34 Ahmad I, Del Debbio CB, Das AV, Parameswaran S: Muller glia: a promising target for therapeutic regeneration. Invest Ophthalmol Vis Sci 2011;52:5758-5764.

35 Hoogland TM, Kuhn B: Recent developments in the understanding of astrocyte function in the cerebellum in vivo. Cerebellum 2010;9:264-271.

- 36 Bringmann A, Pannicke T, Biedermann B, Francke M, Iandiev I, Grosche J, Wiedemann P, Albrecht J, Reichenbach A: Role of retinal glial cells in neurotransmitter uptake and metabolism. Neurochem Int 2009;54:143160 .
37 Eng LF, Gerst lB, Vanderhaeghen JJ: A study of proteins in old multiple sclerosis plaques. Trans Am Soc Neurochem 1970;1:42.

38 Eng LF, Ghirnikar RS, Lee YL: Glial fibrillary acidic protein: GFAP-thirty-one years (1969-2000). Neurochem Res 2000;25:14391451.

39 Bachoo RM, Kim RS, Ligon KL, Maher EA, Brennan C, Billings N, Chan S, Li C, Rowitch DH, Wong WH, DePinho RA: Molecular diversity of astrocytes with implications for neurological disorders. Proc Natl Acad Sci USA 2004;101:8384-8389.

40 Yeh TH, Lee da Y, Gianino SM, Gutmann $\mathrm{DH}$ : Microarray analyses reveal regional astrocyte heterogeneity with implications for neurofibromatosis type 1 (NF1)-regulated glial proliferation. Glia 2009;57:1239-1249.

-41 Doyle JP, Dougherty JD, Heiman M, Schmidt EF, Stevens TR, Ma G, Bupp S, Shrestha P, Shah RD, Doughty ML, Gong S, Greengard P, Heintz N: Application of a translational profiling approach for the comparative analysis of cns cell types. Cell 2008;135:749-762.

42 McCarthy KD, de Vellis J: Preparation of separate astroglial and oligodendroglial cell cultures from rat cerebral tissue. J Cell Biol 1980;85:890-902.

43 Cahoy JD, Emery B, Kaushal A, Foo LC, Zamanian JL, Christopherson KS, Xing Y, Lubischer JL, Krieg PA, Krupenko SA, Thompson WJ, Barres BA: A transcriptome database for astrocytes, neurons, and oligodendrocytes: a new resource for understanding brain development and function. J Neurosci 2008;28:264-278.

-44 Tsai HH, Li H, Fuentealba LC, Molofsky AV, Taveira-Marques R, Zhuang H, Tenney A, Murnen AT, Fancy SP, Merkle F, Kessaris N, Alvarez-Buylla A, Richardson WD, Rowitch DH: Regional astrocyte allocation regulates CNS synaptogenesis and repair. Science 2012;337:358-362.

45 Olsen ML, Campbell SL, Sontheimer H: Differential distribution of Kir4.1 in spinal cord astrocytes suggests regional differences in $\mathrm{K}^{+}$homeostasis. J Neurophysiol 2007;98: 786-793.

46 Schipke CG, Ohlemeyer C, Matyash M, Nolte C, Kettenmann H, Kirchhoff F: Astrocytes of the mouse neocortex express functional N-methyl-D-aspartate receptors. FASEB J 2001;15:1270-1272.

47 Ziak D, Chvatal A, Sykova E: Glutamate-, kainate- and NMDA-evoked membrane currents in identified glial cells in rat spinal cord slice. Physiol Res 1998;47:365-375.

48 Muller T, Grosche J, Ohlemeyer C, Kettenmann H: NMDA-activated currents in Bergmann glial cells. Neuroreport 1993;4:671674.

49 Seifert G, Steinhauser C: Glial cells in the mouse hippocampus express AMPA receptors with an intermediate $\mathrm{Ca}^{2+}$ permeability. Eur J Neurosci 1995;7:1872-1881.
50 D’Ambrosio R, Wenzel J, Schwartzkroin PA, McKhann GM 2nd, Janigro D: Functional specialization and topographic segregation of hippocampal astrocytes. J Neurosci 1998; 18:4425-4438.

51 Houades V, Koulakoff A, Ezan P, Seif I, Giaume C: Gap junction-mediated astrocytic networks in the mouse barrel cortex. Neurosci 2008;28:5207-5217.

52 Hertz L: Functional interactions between neurons and astrocytes. 1. Turnover and metabolism of putative amino acid transmitters. Prog Neurobiol 1979;13:277-323.

53 Tanaka J, Ichikawa R, Watanabe M, Tanaka $\mathrm{K}$, Inoue Y: Extra-junctional localization of glutamate transporter EAAT4 at excitatory Purkinje cell synapses. Neuroreport 1997;8: 2461-2464

54 Choi DW, Maulucci-Gedde M, Kriegstein AR: Glutamate neurotoxicity in cortical cell culture. J Neurosci 1987;7:357-368.

55 Furuta A, Rothstein JD, Martin LJ: Glutamate transporter protein subtypes are expressed differentially during rat CNS development. J Neurosci 1997;17:8363-8375.

56 Berger UV, Hediger MA: Comparative analysis of glutamate transporter expression in rat brain using differential double in situ hybridization. Anat Embryol (Berl) 1998;198: 13-30.

57 Shibata T, Yamada K, Watanabe M, Ikenaka $\mathrm{K}$, Wada K, Tanaka K, Inoue Y: Glutamate transporter glast is expressed in the radial glia-astrocyte lineage of developing mouse spinal cord. J Neurosci 1997;17:9212-9219.

58 Regan MR, Huang YH, Kim YS, Dykes-Hoberg MI, Jin L, Watkins AM, Bergles DE, Rothstein JD: Variations in promoter activity reveal a differential expression and physiology of glutamate transporters by glia in the developing and mature CNS. J Neurosci 2007;27:6607-6619.

59 Yang Y, Vidensky S, Jin L, Jie C, Lorenzini I, Frankl M, Rothstein JD: Molecular comparison of GLT1+ and ALDH1L1+ astrocytes in vivo in astroglial reporter mice. Glia 2011;59: 200-207.

60 Deneen B, Ho R, Lukaszewicz A, Hochstim CJ, Gronostajski RM, Anderson DJ: The transcription factor NFIA controls the onset of gliogenesis in the developing spinal cord. Neuron 2006;52:953-968.

61 Pringle NP, Yu WP, Howell M, Colvin JS, Ornitz DM, Richardson WD: FGFR3 expression by astrocytes and their precursors: evidence that astrocytes and oligodendrocytes originate in distinct neuroepithelial domains. Development 2003;130:93-102.

62 Owada Y, Yoshimoto T, Kondo H: Spatiotemporally differential expression of genes for three members of fatty acid binding proteins in developing and mature rat brains. J Chem Neuroanat 1996;12:113-122.

-63 Anthony TE, Klein C, Fishell G, Heintz N Radial glia serve as neuronal progenitors in all regions of the central nervous system. Neuron 2004;41:881-890. 
64 Stolt CC, Lommes P, Sock E, Chaboissier MC, Schedl A, Wegner M: The Sox9 transcription factor determines glial fate choice in the developing spinal cord. Genes Dev 2003; 17:1677-1689.

65 Ulloa F, Briscoe J: Morphogens and the control of cell proliferation and patterning in the spinal cord. Cell Cycle 2007;6:2640-2649.

-66 Kang P, Lee HK, Glasgow SM, Finley M, Donti T, Gaber ZB, Graham BH, Foster AE, Novitch BG, Gronostajski RM, Deneen B: Sox9 and NFIA coordinate a transcriptional regulatory cascade during the initiation of gliogenesis. Neuron 2012;74:79-94.

-67 Bonaguidi MA, McGuire T, Hu M, Kan L, Samanta J, Kessler JA: LIF and BMP signaling generate separate and discrete types of GFAP-expressing cells. Development 2005; 132:5503-5514.
68 Sahni V, Mukhopadhyay A, Tysseling V, Hebert A, Birch D, McGuire TL, Stupp SI, Kessler JA: BMPR1a and BMPR1b signaling exert opposing effects on gliosis after spinal cord injury. J Neurosci 2010;30:1839-1855.

69 Garcia AD, Petrova R, Eng L, Joyner AL: Sonic hedgehog regulates discrete populations of astrocytes in the adult mouse forebrain. J Neurosci 2010;30:13597-13608.

70 Zhou Q, Wang S, Anderson DJ: Identification of a novel family of oligodendrocyte lineage-specific basic helix-loop-helix transcription factors. Neuron 2000;25:331-343.

$>71$ Lu QR, Yuk D, Alberta JA, Zhu Z, Pawlitzky I, Chan J, McMahon AP, Stiles CD, Rowitch $\mathrm{DH}$ : Sonic hedgehog - Regulated oligodendrocyte lineage genes encoding bhlh proteins in the mammalian central nervous sys tem. Neuron 2000;25:317-329.

$>72$ Zhou Q, Anderson DJ: The bHLH transcription factors OLIG2 and OLIG1 couple neuronal and glial subtype specification. Cell 2002;109:61-73.
73 Lu QR, Sun T, Zhu Z, Ma N, Garcia M, Stiles CD, Rowitch DH: Common developmental requirement for Olig function indicates a motor neuron/oligodendrocyte connection. Cell 2002;109:75-86.

74 Muroyama Y, Fujiwara Y, Orkin SH, Rowitch $\mathrm{DH}$ : Specification of astrocytes by bHLH protein SCL in a restricted region of the neural tube. Nature 2005;438:360-363.

75 Hochstim C, Deneen B, Lukaszewicz A, Zhou Q, Anderson DJ: Identification of positionally distinct astrocyte subtypes whose identities are specified by a homeodomain code. Cell 2008;133:510-522.

76 Herculano-Houzel S: The human brain in numbers: a linearly scaled-up primate brain. Front Hum Neurosci 2009;3:31

77 Foo LC, Allen NJ, Bushong EA, Ventura PB, Chung WS, Zhou L, Cahoy JD, Daneman R, Zong H, Ellisman MH, Barres BA: Development of a method for the purification and culture of rodent astrocytes. Neuron 2011;71: 799-811. 